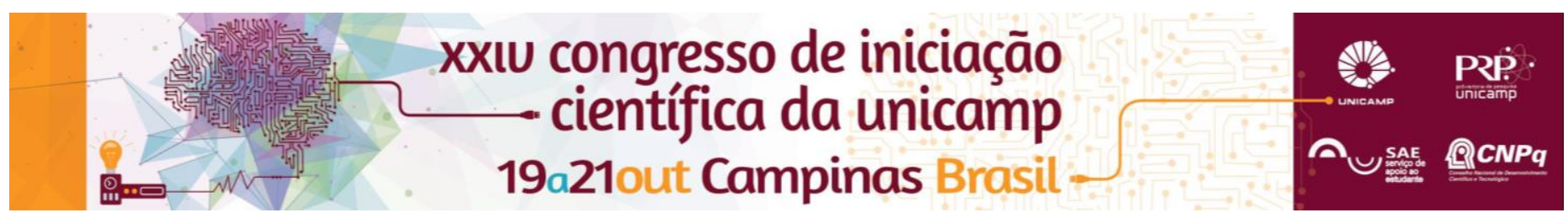

\title{
SHADOW THE LIGHT OF VOICE: The Mechanisms of Severe and Acute
}

\author{
Tainã Filipe Araujo*, Gina M. M. Aguilar.
}

\begin{abstract}
This project aims to relate the work with the human voice, developed by Alfred Wolfsohn and his student and actor, Roy Hart, especially in the behave of deep voice and high pitch, with the concepts of anima, animus and shadow formulated by the psychologist Carl Gustav Jung. Wolfsohn after taking part in the First World War, developed a research facing the expression. Roy Hart absorve those teachings and brings then to the theatrical ambient. Jung's works, about anima, animus and shadow, served as the theoretical base in order to analyse the theoretical-pratical to be developed in this work.
\end{abstract}

\section{Key words:}

Voice, Theater, Alfred Wolfsohn, Roy Hart, Carl Gustav Jung.

\section{Introduction}

This research aimed to get a first theoretical-practical and tangible-vocal contact with the teachings left by Alfred Wolfsohn and Roy Hart, establishing a relationship with the concepts of anima, animus and shadow, developed by Carl G. Jung.

\section{Results and Discussion}

The methodology used to develop this Scientific Initiation took place in three stages. The first included the reading of theoretical works, providing support for research. The second step was to interview a researcher Wolfsohn and Hart and a Jungian psychologist. The third was a practical observation, with volunteers voice in extremi and relate it to the theoretical parts.

We used stretching exercises and warm the body/voice, relaxation areas of mental and bodily tension, and the use of taught theater games in class by teacher Gina Aguilar with the intention to analyze the voice in situations in extremi, between other breathing exercises, flow and energy change of the body/voice. Subsequently, in order to assess these practices - the actor's point of view - a study was carried out in common, text Novas Diretrizes em Tempos de Paz, by Bosco Brazil.

The results achieved bolster on the three north that have guided this SI. Thus, it was possible to observe how the voice can be explored and expanded, given their psychophysical dimensions within the sound spectrum. Despite vocal blockages that volunteers have in their daily lives, their voices were guided to an extra level daily and gave up the recognition of new sonorities.

The use of social archetypes employed by Jung, and their concepts of anima, animus and shadow were important in the search for clearer images that could bring more interaction with what was proposed.
Alfred Wolfsohn, Roy Hart and Carl G. Jung and the poetic and technical development that an actor needs to have. I believe in the importance of dissemination of this research in Brazil, it is still little explored, which denotes a nonsense before everything was and is achieved not only by these three researchers, but by all scholars in their various fields and backgrounds.

Before the institutional support that saw my potential to be worked and how much it helped me in the actor-researcher process, although it has been working on a more panoramic level when compared with the methods used in the Roy Hart Theater and the RoyHartTeachers.

Explore the use of the deep voice/high pitch is not a mere vocal exhibitionism, as Paula Molinari said. When working well, it shows how a complex thought to be present in all, or at least live in this search (MOLINARI, 2008, pg 75).

\section{Acknowledgement}

The precious women involved in this work that both helped me: Professor Gina Aguilar for guidance; psychologist and friend, Caroline Oliveira, the interview and conversation about human life; Master Professor Leticia Chiochetta the interview and the book and presented; my mother, Mrs. Maria Cruz by semantic revisions in my project and report, thank you. Finally, many women in the poetry group Meeting of the Waters, I had the pleasure to work in 2008 with a scenic exercise both spoke to the theme of our research developed.

This research, first of all, is the result of what you taught me, so in addition to dedicate it to you, I say that all this was done by all of you.

\section{Conclusions}

I noted the importance of this research to human development, intrinsic to what is proposed by 